\title{
A FORMAÇÃO DO PROFESSOR PESQUISADOR NOS CURSOS DE LICENCIATURA DA UERJ/CEDERJ: O LUGAR E A IMPORTÂNCIA DA PESQUISA NO CURSO DE FORMAÇÃO EM LICENCIATURA EM GEOGRAFIA DA UERJ/CEDERJ NO SISTEMA SEMIPRESENCIAL
}

\author{
RESEARCHER TEACHER'S TRAINING IN UNDERGRADUATE COURSES AT UERJ/CEDERJ: THE PLACE AND IMPORTANCE \\ OF RESEARCH IN GEOGRAPHY MAJOR IN THE SEMI-PRESENTIAL SYSTEM
}

\section{RESUMO}

O presente trabalho tem como objetivo apresentar um panorama de como o conhecimento produzido nas diferentes disciplinas do curso de Licenciatura em Geografia da UERJ/CEDERJ, modalidade semipresencial, propicia a construção de um professor pesquisador focada na relação teoria-prática, dispondo de elementos facilitadores que permitem que esse profissional se torne um produtor de conhecimento. Assim, tomamos como ponto de partida alguns aspectos teóricos do processo de formação de professores na licenciatura e a concepção de professor reflexivo (SCHON, 1990). A partir de atividades oferecidas aos alunos do curso de licenciatura - Seminários de Pesquisa e curso de Técnicas de Pesquisa -, acreditando serem estas relevantes no processo de construção de uma consciência sobre suas práticas futuras, foi feita uma sondagem com os alunos dos polos onde o curso de Geografia é ministrado, com o intuito de verificar até que ponto o curso vem propiciando a formação de um professor pesquisador.

Palavras-chave: Formação; Professor Pesquisador; Licenciatura; Geografia UERJ/CEDERJ; Pesquisa no sistema semipresencial.

\section{ABSTRACT}

This study present an overview of how knowledge produced in subjects of Geography major at UERJ/CEDERJ makes possible to train its students as a researcher teacher in a semi-presential study modality, focused on the relationship between theory and practice and aimed at making easier to them to become knowledge producers as well. The starting point of the study includes theoretical aspects of teacher's university training and the concept of reflective teacher (SCHÖN, 1990). A survey conducted with the students at centers (polos) where there is Geography major aimed to verify the extent to which they are being educated to be researcher teachers. With the premise of relevance to the building of awareness of teacher's future practices, such survey took place in activities offered to undergraduates (in Seminars on Research course and Research Techniques course).

Keywords: Researcher Teacher's Training; Licentiate degree; UERJ/CEDERJ Geography major; Research in semi-presential modality.

\author{
D Glaucio José Marafon ${ }^{\text {a }}$ \\ D José Silvan Borborema Araújo a,b \\ D Vanilda M. S. Teófilo ${ }^{a, b}$ \\ ${ }^{a}$ Universidade do Estado do Rio de \\ Janeiro (UERJ), Rio de Janeiro, RJ, Brasil \\ ${ }^{\text {b }}$ Centro de Educação Superior a \\ Distância do Estado do Rio de Janeiro \\ (CEDERJ), Rio de Janeiro, RJ, Brasil
}

DOI: 10.12957/geouerj.2020.48437

Correpondência:

glauciomarafon@hotmail.com

Recebido em: 30 out. 2019 Revisado em: 27 nov. 2019 Aceito em: 6 jan.2020

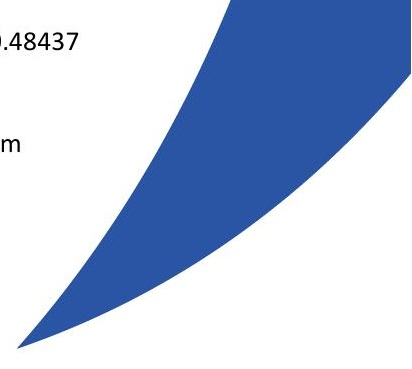




\section{INTRODUÇÃO}

Este artigo é resultado de uma prática que vem sendo exercitada no curso de formação de licenciandos, na modalidade semipresencial em Geografia da UERJ/CEDERJ, colocando a pesquisa como uma das questões prioritárias e centrais dessa formação.

Bem sabemos que este tema - o professor pesquisador - é bastante discutido pela comunidade educacional como um todo, estando presente em obras de inúmeros estudiosos. Todavia, mesmo aparecendo em projetos, leis e planos governamentais e tendo sua importância reconhecida, nem sempre ocorre sua prática efetiva nos cursos de formação de professores.

Em nossa realidade, a questão central é como articular pesquisa e prática no curso de licenciatura em Geografia no sistema semipresencial que pretende propiciar a formação de um professor pesquisador, entendendo ser essa uma articulação possível. A nossa trajetória enquanto profissionais que trabalham em espaços de educação e de políticas de formação de professores - em que saberes relativos ao oficio de educador foram construídos com alunos e professores - nos permite afirmar que é no âmago da licenciatura que se aflora a questão do saber e da pesquisa.

Entendendo a pesquisa como componente necessário e fundamental na formação docente, temos a preocupação em preparar os futuros professores para realizá-la, estimulando-os não só a se dedicarem à sua prática, mas, sobretudo, entenderem sua importância, enfatizando a necessidade e a possibilidade da atividade de pesquisa no campo da Geografia.

É importante salientar que, enquanto somos interessados na relação pesquisa-docência, tomamos como ponto de partida para análise e estudo dois aspectos teóricos: o processo de formação de professores nas licenciaturas e a concepção de professor reflexivo, lançada por Donald Schon (1990), entendida como uma postura e reflexão sobre a prática que se inicia com a preparação para a docência nos cursos de licenciatura.

Acreditamos, conforme Callai (2013, p. 121), que

o curso de graduação deve permitir aos licenciados que exercitem uma prática de sala de aula que não seja a mera repetição de conteúdos transmitidos a cada semestre, mas com uma linha metodológica que articule o ensino e a pesquisa.

Destarte, esse artigo tem como objetivo apresentar um panorama de como o conhecimento produzido em disciplinas do curso de Geografia se constitui como uma prática de pesquisa e como ciência, apontando os elementos facilitadores que permitem que um professor se torne um produtor de conhecimento, sendo esta a razão pela qual não se pode dissociar a trajetória do curso a formação de um professor pesquisador. 


\section{POLITICAS E PROCESSOS DE FORMAÇÃO DE PROFESSORES}

Objetivamos manter uma breve discussão em torno do impacto das políticas historicamente implementadas no Brasil e suas repercussões na formação de professores, investigação que ganha relevância dentro deste trabalho, tendo em vista que o exercício de uma prática reflexiva é algo possível de ser concretizado desde que a formatação dos cursos de licenciatura caminhe nessa direção.

Nossa pretensão, neste momento, é a de resgatar o estudo da origem da formação de professores e os fundamentos que têm servido de base para apoiar as políticas desta formação no Brasil e mostrar a grande importância pela busca de alternativas que nos auxiliem no deslocamento de uma prática conservadora que vem formando os licenciandos como técnicos a serem preparados para o exercício da docência (TÉOFILO, 2002, p. 21).

Nessa direção, ao estudar a evolução dos diferentes momentos dessa formação, afirma Teófilo (2002) que os cursos de licenciatura foram marcados por políticas distintas - externas e internas - nos diferentes momentos históricos e, ainda que não intencional, o impacto delas trouxe consequências para os espaços de formação.

Numa breve análise das diferentes formatações dos cursos de Licenciatura, começando pelas antigas dicotomias expressas nos cursos de Pedagogia (dividido por habilitações) e nas licenciaturas em geral (esquema " $3+1$ ", separando conteúdo específico da formação pedagógica), passando pela indicação de uma base comum nacional - com um corpo de conhecimentos fundamentais à construção da identidade profissional docente -, chegando aos dispositivos legais mais recentes, permite constatar "uma atmosfera de confusão e complexidade que vem se perpetuando ao longo da história da formação de professores" (TEÓFILO, 2007, p. $32)$.

Tentando explorar essas considerações, sentimos a necessidade de voltar às condições em que vem se dando o processo de formação docente, com uma inadequação visível nos diferentes momentos históricos, indicada por um número significativo de estudos. Fruto de profundas modificações nas políticas que adotaram a prática da importação de modelos (influências estrangeiras), o impacto deixou os cursos à mercê de leis, pareceres e decretos que, por não terem sido criados no interior dos processos, desconsideraram os saberes e experiências dos professores - fatos que causaram um emaranhado de distorções -, redundando na discriminação e na marginalidade que vêm plasmando a educação brasileira.

Nesse encaminhamento, vamos encontrando explicação para os motivos que ajudaram a consolidar uma perspectiva tradicional e individualizante, nos cursos de formação, com ênfase na transmissão de conhecimentos, quando se constatou que os mesmos estão alocados na docência (base para o ensino e para os espaços de formação). 
O que se depreende dessa análise é a necessidade de se entender o saber docente como uma prática social e política (Senna, 2002), que pressupõe rupturas com o que está posto nos espaços de formação, havendo necessidade de uma reengenharia, uma nova inteligibilidade e maior permeabilidade, até porque a pluralidade de campos científicos trouxe como consequência a necessidade de busca de novas formas de conhecimentos.

O contexto atual abre reflexões que alargam o horizonte para inúmeras questões, apresentando desafios que nos colocam diante de um pano de fundo complexo e desafiador - de um lado, as marcas de uma realidade histórica repleta de contradições; de outro, a necessidade de se alterar o processo formativo. Este último exige disposição e compromisso com uma educação de qualidade pensada com criticidade, na certeza de que será concretizada por meio do diálogo e da interação entre sujeitos que se constroem - dando ao professor - ainda que com precariedades intelectuais e materiais - um papel político e transformador, oferecendo-Ihe condições de potencializar suas dificuldades em direção a um trabalho pedagógico de qualidade.

O cumprimento e a convocação para essa tarefa exigem o compromisso com uma política séria de educação de qualidade, com a co-responsabilidade por um projeto de formação de licenciandos que integre investimentos e por meio do qual os educadores terão a obrigação de fazer com que mais educandos se tornem cada vez mais qualificados e mais professores possam ser formados com competência para educar novas geração de alunos numa via de mão dupla (TEÓFILO, 2002 p. 34).

Os estudos desenvolvidos pela referida autora eliminam qualquer suspeita de que haja sintonia fina entre políticas e formação de professores e, ainda, segundo ela, a situação desfavorável desses cursos aponta para a necessidade de sua reestruturação, até porque a "deterioração na qualidade desses cursos chegou a níveis alarmantes" (MELLO, 1998, p. 37).

Nesse sentido, a literatura indica a necessidade de preparar os professores como condição quase que exclusiva da melhoria da qualidade de ensino. Caberia lembrar que estes não respondem sozinhos pelos fracassos da escola, razão pela qual não adianta culpabilizá-los mais uma vez, porque atrás deles estão as políticas educacionais (TEÓFILO, 2002).

Esse desprestígio vem de longa data, pois, como aponta Nóvoa (1991, p. 139), “a formação profissional insuficiente, a falta de condições de trabalho, os baixos salários e os atrasos são questões que continuam colocando os professores em desvantagem frente a outras profissões".

Assim, sem maiores aprofundamentos, um projeto que chegou a colocar em questão a competência dos espaços formativos e que criou uma dissintonia entre as políticas implementadas e o processo educacional 
exige a necessidade de modificações, diferentes daquelas que vêm sendo implementadas nos espaços formativos.

Desse modo, estamos pressupondo que, independentemente da definição da formatação dos cursos de licenciatura, temos que definir com clareza o tipo de professor que queremos e que estamos tentando formar - o professor pesquisador no curso de licenciatura semipresencial da UERJ.

Para uma maior compreensão dessa situação, chegamos aos estudos de Menezes (2015) que, ao analisar a realidade atual do ensino da Geografia, aponta para o descompasso e o distanciamento na relação entre duas vertentes - o ensino da Geografia Escolar e o da Acadêmica, articulação esta que, em nossa visão, seria fundamental para o desenvolvimento de uma geografia preocupada com as problemáticas socioespaciais, econômicas, políticas e culturais presentes no cotidiano da população, pois como já alertava Callai $(1995$, p. 41):

\begin{abstract}
A pesquisa num curso de graduação e na realização do exercício profissional, no caso do magistério, deve se dar no sentido da formação de um profissional autônomo, capaz de conduzir o seu trabalho e capaz de ter o domínio dos processos que envolvem a aprendizagem. O professor deve ele próprio construir, então o seu (um novo) conhecimento no cotidiano do seu trabalho, a partir dos pressupostos, e do objeto da ciência, quer dizer, do conhecimento que ele tem (ou a que tem acesso) e da análise crítica que realiza na prática docente.
\end{abstract}

\title{
O LUGAR DA PESQUISA NA FORMAÇÃO DOCENTE
}

Iniciamos nossa reflexão mostrando a importância desses conceitos que trouxeram inegáveis conquistas e avanços para a educação de uma forma geral. Nesse encaminhamento, apresentaremos uma breve análise dos conceitos de professor pesquisador e professor reflexivo, com seus pressupostos e fundamentos, mostrando não só suas possibilidades, como também limitações, no sentido de potencializar os professores e sistemas educativos, visando a uma escola democrática e justa.

Sem dúvida, são termos que vêm ocupando boa parte da vida profissional de muitos daqueles que trabalham com formação de professores e que lutam pela valorização da docência. O que percebemos, de início, é a existência de uma fonte teórica comum, representada pelos trabalhos de Donald Schon, "o reflexive practitioner", que teve influência marcante no Brasil (LUDKE, 2001).

O distanciamento entre os espaços de formação e os de prática levou Donald Schon a pensar num outro modelo de curso que ultrapassasse os conhecimentos elaborados pela ciência, posto que assentado na ciência moderna. Assim, formulou o conceito de "professor reflexivo", baseado na "epistemologia da prática", acreditando que o profissional formado nessa perspectiva poderia dar conta dos problemas com que se depara no dia a dia, diminuindo, assim, as tensões entre os espaços de teoria e os de prática (PIMENTA, 2006, p. 19). 
Assim, a epistemologia da prática voltada para a prática docente trazia duas exigências: um professor que refletisse, analisasse e problematizasse sua a ação e a indicação de que este "lócus" seria a própria Escola, entendida como um lugar de construção de conhecimento.

Inegavelmente, essa epistemologia resgata a valorização do profissional, potencializando e reconhecendo o seu saber (construído no cotidiano) até então desconsiderado pelos espaços de teoria; ao mesmo tempo e como desdobramento, traz à luz a questão da relação teoria-prática ainda opaca e, portanto, não solucionada pelos cursos de formação, estando aqui a conexão entre os conceitos acima.

Ao que tudo indica, o professor formado nessa perspectiva teria condições de refletir e encontrar soluções mais criativas para um contexto rico e plural. Claro que, num contexto onde os cursos de formação - modelados numa perspectiva técnica - clamavam por mudanças, claro está que esse conceito foi rapidamente absorvido; a epistemologia da prática encontrava as condições favoráveis para sua expansão. Nela, o professor poderia "mobilizar um conhecimento na ação, no dia a dia, configurando um hábito" (PIMENTA, 2006, p. 20).

Não nos parece nada simples a incorporação dessa epistemologia nas práticas docentes. Ainda que reconhecendo-a como de grande impacto, com contribuições inúmeras para os nossos cursos de formação, sua operacionalização esbarra num primeiro obstáculo - um modelo de curso que tem uma lógica pragmática e racionalista, pouco preocupada em formar profissionais que possam colaborar com mudanças necessárias ao país, e de acordo com Mello (1998, p. 201): “Nossos cursos estão centrados na capacitação técnica, desconsiderando as relações entre a educação e outros processos sociais que a formação puramente profissional do professor nem sempre permite adquirir."

Sem entrar em pormenores, pretendemos afirmar que o problema dos cursos de formação de professores vem se agravando desde 1970. Se, na ocasião, o problema se resumia em saber onde e quando formar o professor, hoje se tornou mais complexo, uma questão estrutural a ser tratada com muita atenção pela Universidade.

Indubitavelmente, a falta de integração entre os institutos de conteúdos específicos e as faculdades de educação evidenciou um distanciamento entre o que e como ensinar, fruto da dicotomia entre Bacharelado e Licenciatura, criando uma desarticulação entre formação acadêmica e realidade prática, fruto da duplicidade de objetivos; a Licenciatura visava formar professores cuja função era traduzir o conhecimento em métodos de ensino e, no Bacharelado, pesquisadores.

Viana (1993) enfatiza que a qualidade da formação do professor está vinculada ao ensinar e pesquisar, relação muitas vezes inexistente na estrutura curricular da licenciatura, situação esta que vem nos desafiando porque mostra que as alterações curriculares, até então implementadas, pouco contribuíram para a 
viabilização de um projeto verdadeiramente formativo que ajude a encurtar a distância entre os espaços de formação e os da prática.

Nessa direção, temos que concordar com Pimenta (2006), o qual afirma que os conceitos de professor reflexivo e professor pesquisador pouco mudaram as práticas docentes, até porque e ao que tudo indica, o espaço de formação precisa introjetar esses conceitos, que é o que pretendemos mostrar em nossa realidade de formação de professores de Geografia.

A constatação de que o contexto em que se encontra a Licenciatura de uma forma geral apresenta-se ainda como desfavorável com problemas que remontam à sua gênese nos leva a defender os conceitos de professor reflexivo e de pesquisador como um caminho para a reconstrução e reinvenção dos espaços formativos, especialmente pela dimensão epistemológica dos mesmos.

Ainda no que se refere ao professor reflexivo, encontramos outro conceito, o de "práxis" e aqui sustentamos a convicção da possibilidade da teoria trazer novas interrogações, contribuindo para um novo olhar sobre aquilo que queremos investigar. Temos que concordar com Pimenta (2006, p.15) quando afirma que o conhecimento teórico não se adquire com um simples olhar, mas é basicamente instrumentalizado pela teoria, devendo "o existente ser tomado como referência", em um movimento de rever para transformar.

Chegamos ao conceito de professor pesquisador, desejando argumentar sobre sua importância, recorrendo, inicialmente, a estudos que procuraram apontar a relação entre pesquisa e a construção do conhecimento, nosso objeto de interesse (LUDKE, 2001; DEMO, 2004). Sem dúvida, um ensino produtivista, focado no repasse de conteúdos, é um elemento dificultador na implementação da pesquisa enquanto componente essencial da docência.

Reforçamos, aqui, que os conceitos de professor reflexivo e de pesquisador têm nas pesquisas desenvolvidas por Schon o seu tronco comum, sendo amplamente expandidos devido ao questionamento acerca da Teoria da Reprodução, que alocou o professor num lugar de sujeito passivo.

Ao conceito de professor reflexivo, somou-se o de "intelectual transformador" (LUDKE, 2001, p. 13), como "aquele que propõe questões sobre o que ensina, sobre a forma como deve ensinar e sobre os objetivos gerais que persegue". Este e outros autores são citados como tendo colocado a pesquisa no centro das atenções, atribuindo um lugar de destaque na prática docente.

Estudiosos como Ludke (2001, p. 99) sinalizam que, embora no discurso "os professores não consigam desvincular a pesquisa da prática docente", na realidade, essa junção ainda inexiste especialmente por não ser clara a concepção que os professores têm de pesquisa; um entendimento amplo que se estende da elaboração do material didático, passando por estratégias de ensino, chegando a programas curriculares. 
Essa talvez tenha sido a razão pela qual tenha sido constatada a inexistência de um vínculo entre as práticas docentes e a pesquisa. Ao estarem focadas no aperfeiçoamento das práticas pedagógicas, os resultados foram pontuais, envolvendo um ou outro profissional e não o coletivo dos espaços educativos escolares, uma condição necessária para tornar a atividade de pesquisa uma rotina que deverá envolver a cultura escolar como um todo.

Não temos dúvida de que o incremento das atividades de pesquisa é um grande desafio a ser enfrentado pelos cursos de formação e, nesse sentido, temos a clareza de que existem potencialidades a serem desenvolvidas nos espaços formativos, podendo, assim, ajudar a formar este tipo de profissional.

É nessa direção que reconhecemos o professor reflexivo e o pesquisador como um caminho para ajudar o professor a pensar a construção do saber, ideia tão inconcebível na ciência do século XX, que trazia uma concepção de sujeito determinista e mecanicista (SCHNITMAN, 1996), o que não mais se sustenta em tempos pós-modernos e cuja direção desemboca no problema da episteme.

As dimensões político-epistemológicas devem ser assumidas por todos os educadores, em um movimento conjunto entre os espaços de formação inicial e os de prática, viabilizando a possibilidade de se discutir a concepção de saber que irá vigorar nos espaços educativos escolares, a fim de tornar os educadores verdadeiros agentes de educação social.

\section{GEOGRAFIA ESCOLAR E GEOGRAFIA ACADÊMICA: UM ENCONTRO POSSÍVEL}

Para melhor esclarecer e responder a finalidade mais geral deste artigo, que é a de formar um professor reflexivo e pesquisador, preocupação recorrente do curso de Geografia semipresencial da UERJ, faremos, a seguir, um breve resgate histórico no contexto da relação entre a Geografia Escolar e Acadêmica.

Pensar a Geografia escolar como uma disciplina articulada com a realidade de vida dos alunos e da escola em geral, que busca uma aproximação no entendimento dos conteúdos ministrados em sala de aula com a geografia desenvolvida na academia, nos possibilita entender sobre a sua trajetória ao longo do tempo histórico, em que atendia a um determinado segmento da sociedade, servindo a determinados governos para conquistas de novos territórios, a exemplo da Alemanha do século XVIII e início do século XIX (MORAES, 1987; MENEZES, 2015).

Nesse contexto, com base nos autores citados, a Geografia escolar já iniciava a ser sistematizada, demonstrando importante serviço para a sociedade alemã, na construção de um sentimento de pertencimento territorial e posterior unificação político-territorial desse país, o que culminaria com a institucionalização da Geografia na academia. 
Diante desse contexto, o nosso interesse é tornar ainda mais claro o entendimento de que o desenvolvimento da Geografia acadêmica enquanto ciência, imprescindível para a compreensão dos acontecimentos ocorridos no espaço, não se faz isolado da Geografia escolar, levando-se em consideração que o conhecimento produzido nas universidades pode e deve ter seus reflexos no ambiente escolar para o desenvolvimento dos conteúdos dessa disciplina e aplicação na vida prática dos alunos.

Nesse sentido, cabe-nos questionar como os cursos superiores de Geografia, em especial os de licenciatura da UERJ, estão articulando o saber acadêmico com o escolar, como a universidade pode estreitar a relação entre a ciência geográfica e a Geografia escolar.

Nesse sentido, como a educação superior a distância tem se comportado diante dessa necessidade de articulação entre teoria e prática vividos no ambiente universitário e escolar?

Vale ressaltar que esse tipo de questionamento se torna cada vez mais pertinente, tendo em vista a velocidade de mudanças ocorridas no espaço e aceleradas com o desenvolvimento das tecnologias. Destarte, as respostas não são estanques; muito pelo contrário, elas ganham forma com o fazer da ciência e necessitam ser aprimoradas constantemente, sendo urgente a sua aplicabilidade no âmbito escolar.

É incontestável a relação da Geografia escolar com a ciência geográfica, tendo em vista que a pesquisa e desenvolvimento da segunda possibilitou um ambiente propício-de acordo com os diversos interesses dos grupos dominantes - para a interação e a aplicabilidade da primeira nos moldes que vemos atualmente.

É nesse contexto que Menezes (2015) defende que os discursos produzidos no ambiente escolar ainda provêm das correntes de pensamento geográfico, levando em consideração os diferentes contextos históricos que influenciaram as tomadas de decisão ao longo do tempo.

Nesse sentido, antes mesmo da Geografia se constituir enquanto ciência, o pensamento geográfico já se desenvolvia com o intuito de estabelecer uma construção identitária entre a população e o espaço em que viviam ou aqueles espaços que estavam sendo conquistados, como foi o caso do processo de construção e unificação alemã, discutidos anteriormente.

Contudo, se tomamos como ponto inicial o estabelecimento da Geografia enquanto ciência, percebemos que, desde Humboldt, as pesquisas focam em determinado aspecto do espaço, não para explicar o fenômeno em si, mas para garantir o domínio sobre o espaço dos grupos dominantes. Isso vale tanto para a Geografia produzida nas universidades como para a Geografia escolar.

Vale ressaltar que mesmo a Geografia tendo sido institucionalizada enquanto ciência no final de século XIX, tal fato só aconteceu no Brasil em início do século XX, com a sistematização dessa ciência por meio da Sociedade Brasileira de Geografia (SBG), o Instituto Brasileiro de Geografia e Estatística (IBGE) e a Universidade 
de São Paulo (USP), ao longo da década de 1930 (MENEZES, 2015). Contudo, a Geografia escolar já tinha sido institucionalizada como disciplina no país muito antes, por volta de 1837, no Colégio Pedro II, na cidade do Rio de Janeiro (GURGEL e SILVA, 2016).

Diante desse cenário, é importante frisar que essa Geografia escolar se dava sob os pressupostos científicos explicativos para cada momento histórico. Assim, em cada período de desenvolvimento do pensamento geográfico, estabelecidos sob os pilares de métodos de pesquisas diferentes, tanto a ciência quanto a disciplina escolar exerciam funções estratégicas para dar respostas aos interesses da elite dominante de cada época, conforme já discutido anteriormente (MENEZES, 2015).

Nesse sentido, a relação pragmática entre ciência geográfica e Geografia escolar se dava de forma ineficaz, tendo em vista que a interação entre ambas se manifestava de maneira fragmentada sobre o espaço porque seu foco eram alguns pontos isolados neste espaço.

A partir da constituição da Geografia crítica, o pensamento científico inclinou-se para uma relação mais intensa com a Geografia escolar, levando em consideração a própria mudança do espaço, o desenvolvimento das tecnologias, o encurtamento do tempo e dos espaços pelo advento de novas formas de circulação e comunicação, entre outros. Essa nova atitude assumida pela Geografia crítica possibilitou uma abertura maior para o entendimento dos diversos aspectos que compõem o espaço e estão contidos nele, embora nem todos os problemas estejam resolvidos com essa corrente. Segundo Menezes (2015, p. 351):

\begin{abstract}
Esta linha teórica dedicou-se a analisar a relação entre a sociedade e a natureza na produção do espaço geográfico. Dessa maneira, diferentemente do pensamento anterior, considerou a realidade como mutável, dinâmica e em permanente movimento. No ensino, esta corrente esteve presente através da ênfase dada à construção do espaço permeado de tensões, conflitos e contradições sociais. Entretanto, a Geografia Crítica ainda possui dificuldades de consolidação no espaço escolar.
\end{abstract}

Dito isso, cabe ressaltar que, mesmo enfrentando dificuldades em se consolidar no espaço escolar, a Geografia Crítica permitiu maior reflexão sobre como essa disciplina se desenvolvia a partir da ideia de espaço mutável, permeado de conflitos e contradições sociais realizado na academia.

Diante desse contexto e ainda apoiados em Menezes (2015), podemos considerar que a partir da década de 1970, com maior influência da Geografia Crítica e, posteriormente, com o desenvolvimento da Geografia Humanista, buscando progressivamente o entendimento dos indivíduos e suas experiências no espaço geográfico, além da retomada dos pressupostos da Geografia Cultural, as discussões acerca de como a Geografia científica e a Geografia escolar poderiam se desenvolver de maneira mais eficiente e articulada ganharam maior relevo.

Sendo assim, o processo de interdisciplinaridade tanto em nível acadêmico, entre a Geografia e as demais ciências, quanto como uma instância importante para o desenvolvimento de uma Geografia escolar, 
que contemple os mais variados aspectos da vida cotidiana dos alunos, relacionando esta disciplina com as demais do currículo, assim como defendido por Farias (2014, p. 59):

Nesses termos, a interdisciplinaridade, em quaisquer das suas perspectivas, procura reestabelecer o diálogo entre os diferentes campos do conhecimento, entender melhor a relação entre o todo e as partes, restituir a integração entre a particularidade e a totalidade, entre unidade e a diversidade, que se perderam sob a imposição dos princípios científicos cartesianos e positivistas.

É tentando romper com esses princípios fechados, focados unicamente na sala de aula e nas questões teórico-conceituais travadas na academia, que o curso de Licenciatura em Geografia UERJ/CEDERJ, na modalidade semipresencial, desenvolve uma série de atividades que aproxima os professores e mediadores a distância dos alunos e seus respectivos polos, num processo constante de formação de um professor pesquisador/reflexivo, como analisado na seção anterior.

Essas atividades propiciam o diálogo entre os atores participantes desse processo de formação, visando não só à formação de estudantes em licenciatura, mas que estes alunos reflitam sobre a prática docente, suas assimetrias e simetrias, consensos e dissensos e como poderão se apropriar dos conteúdos discutidos em sala de aula e introduzi-los no ambiente escolar, de modo que esse conhecimento adquirido na academia tenha utilidade prática na vida dos alunos.

Nesse sentido, destacamos a importância desse movimento promovido pelo curso de Licenciatura em Geografia UERJ/CEDERJ, que busca desenvolver nos seus discentes a consciência reflexiva sobre as suas ações e, consequentemente, sobre as suas futuras práticas enquanto docentes. Assim, os diálogos e trocas de experiências que ocorrem no Seminário de Pesquisa e no minicurso sobre Técnicas de Pesquisa desenvolvem um papel muito importante nessa construção reflexiva.

\section{LINHAS DE ORIENTAÇÃO PARA OS PROCESSOS DE FORMAÇÃO DE PROFESSORES DE GEOGRAFIA}

Para estimular a formação de um professor-pesquisador, além das disciplinas específicas e, entre elas, Teoria e Prática em Geografia (ofertadas nos oito períodos do curso), o grupo de Teoria e Prática Geográficas (TPGs) tem se esforçado em busca de uma revisão constante dos seus princípios, fundamentos e práticas, trabalhando com a pedagogia dialógica, a caminho da concretização de um projeto, o qual acreditamos ser verdadeiramente inclusivo.

A disciplina Teoria e Prática em Geografia (TPG) é oferecida em todos os períodos do curso e pretende realizar a transposição entre o saber teórico oferecido pela universidade e a prática do docente em sala de aula. Como a disciplina é disponibilizada nos oito períodos regulamentares do curso, há uma sequência na apresentação de suas atividades, de acordo com o nível de aprendizagem que se espera para o graduando em cada fase de sua vida acadêmica. 
Além dessa formação, semestralmente é ofertado nos polos o curso de "Técnicas de Pesquisa", que visa proporcionar aos licenciandos um panorama geral e complementar sobre as etapas de investigação científica. São abordados os passos para a construção de um projeto de pesquisa, são apresentadas todas as etapas para a construção de um projeto, com o estímulo de atividades práticas para que o aluno construa um problema de pesquisa, hipótese e/ou questão norteadora da investigação, objetivos, procedimentos metodológicos, fontes de pesquisa e normas de apresentação de um trabalho científico. Essas atividades permitem que o aluno possua autonomia na construção de sua agenda de pesquisa na sua vida profissional. Essa atividade tem se mostrado fundamental para que os nossos licenciados possam ter autonomia no exercício de sua prática profissional como professor-pesquisador.

Em pesquisa realizada com os egressos, mais de $90 \%$ se sentem seguros para exercer a sua atividade profissional, $70 \%$ acreditam que o curso contribui para a sua formação e atuação profissional e $76 \%$ têm a percepção de que o curso os preparou para atuarem com autonomia e com responsabilidade no mercado de trabalho. Esses dados reforçam a importância da oferta de cursos extracurriculares, como o de "Técnicas de Pesquisa", que auxiliam na formação de um professor-pesquisador engajado com a sua realidade.

O "Seminário de Pesquisa", realizado na UERJ - campus Maracanã -, é o momento de apresentação, por parte dos alunos, dos resultados parciais de suas pesquisas. São apresentados para professores e mediadores, em um primeiro momento, os projetos de pesquisas, e, em um segundo momento, o andamento das pesquisas relativas aos trabalhos de final de curso. É o momento em que os alunos dos seis polos apresentam suas pesquisas aos colegas e professores.

Destarte, propomos ao licenciando um trabalho com estrutura dialógica e colaborativa no contexto de uma prática reflexiva - acreditamos ser esse, sem dúvida, um caminho de formação de um futuro educador reflexivo -, direciona-se o projeto de pesquisa para o tema do trabalho de conclusão do curso, visando demonstrar para o licenciando que "investigar é pesquisar e que a pesquisa deve desenvolver o aprender a pensar [...]" (PONTUSCHKA, N. N.; PAGANELLI, T. I.; CACETE, 2009, p. 96). Busca-se, assim, a valorização ampliada dos futuros profissionais de Geografia para que cumpram suas funções sociais e que possam atuar na mediação da construção do conhecimento.

Observando a literatura que discute e analisa a prática do professor em sala de aula enquanto ator que promove e estimula o conhecimento e, mais que isso, que busca pensar a sua prática a partir da realidade escolar e da comunidade na qual está inserido, o curso de Geografia da UERJ/CEDERJ vem estimulando esse pensamento crítico com os seus alunos e futuros professores.

Vários movimentos são feitos nesse sentido de promover a aproximação entre o corpo docente e discente, com atividades que estimulem o pensamento crítico desses estudantes, estimulando-os a refletir 
sobre como o professor pode atuar como um ser reflexivo em sala de aula, pensando sobre sua prática, como articular o teórico e empírico e assim aprimorá-la.

Nessa direção, como forma prática de aproximação entre teoria e prática, além de sua visão interdisciplinar, o curso de Geografia vem promovendo, nos seis polos em que atua, atividades que estimulam a discussão sobre teoria e prática; como exemplo, o minicurso sobre técnica e pesquisa em Geografia e o seminário de pesquisa. A primeira atividade vem contando com a participação de tutores a distância e presenciais, coordenadores de polos e tendo como objetivo promover a discussão sobre os principais problemas encontrados pelos alunos no que diz respeito à elaboração de projetos de pesquisa, monografia, entre outros trabalhos técnicos que venham a desenvolver.

Leva-se em consideração também a rica troca de experiência entre os indivíduos envolvidos nesse trabalho, uma vez que a maioria dos tutores e alunos não se conhecia pessoalmente, além dos tutores não conhecerem a realidade de cada polo. Por isso, essa aproximação promoveu a reflexão, por parte desses atores, de como se encontra estruturado o curso de Geografia na modalidade semipresencial e como as diferentes realidades encontradas podem interferir no resultado de aprendizado no futuro.

É interessante escutar o campo e tirar conclusões a respeito das atividades implementadas e suas repercussões na formação dos licenciandos. A experiência do aluno enquanto ativo e coparticipante na sua capacitação torna-se, então, sobremodo, importante como fonte de informação.

Diante desse contexto, apresentamos, nesse trabalho, uma análise interpretativa de depoimentos obtidos com alguns participantes desse curso, no sentido de discutirmos a importância de exercitar o pensamento crítico sobre as nossas práticas, no intuito de formarmos profissionais preocupados com a realidade socioeconômica, política e cultural em que estamos inseridos, além de trabalhar essa diversidade em sala de aula, respeitando a realidade de cada aluno. Por isso, a aproximação entre a Geografia produzida na academia com a que está sendo construída nas escolas se torna de extrema importância, porque, como discutido ao longo do texto, a Geografia escolar está mais próxima da realidade dos indivíduos, na qual os acontecimentos e mudanças em variadas escalas chegarão mais rápido à vida das pessoas, influenciando-as de variados modos.

Nesse sentido, podemos perceber que o curso de Geografia em questão vem desempenhando esse papel muito bem e se fortalecendo a cada ano, desenvolvendo atividades que estimulam esse pensamento reflexivo e interdisciplinar nas práticas dos seus professores e alunos, buscando estratégias de aproximação entre o saber acadêmico e escolar. 
Apresentamos tal consulta/estudo com base na qual se possa sustentar a necessidade da formação de um professor reflexivo e pesquisador, algo possível de ser concretizado quando as ações implementadas caminham nesta direção; daí, a relevância da mesma dentro de nossa reflexão.

Por esse caminho, apostamos em uma breve linha de análise qualitativa e interpretativa que possibilitasse uma articulação dos dados levantados em campo com os estudos teóricos realizados. Nessa direção, foram ouvidos alunos dos seis polos onde o curso de Licenciatura em Geografia é realizado. A saber: Natividade, Nova Friburgo, Barra do Piraí, Três Rios, Niterói e Campo Grande.

Atualmente (2019.2), temos 1.314 alunos com matrícula ativa no curso de Geografia, sendo 1.271 de 73 dos 92 municípios fluminenses, e 43 alunos com residência nos estados de MG, SP e ES, conforme mapa 1. Somente os alunos inscritos em TG VII e Monografia são convidados a apresentar os resultados de suas pesquisas, que resultarão no trabalho final de curso. Essa sistemática permite a troca de informações entre os professores, mediadores e alunos, contribuindo para uma reflexão mais consistente das investigações realizadas. Durante a realização do seminário, os alunos são convidados a responderem uma sondagem sobre o formato do seminário. A seguir, apresentaremos alguns resultados dessa pesquisa.

Figura 1. Mapa com origem dos alunos por polos - CEDERJ. Fonte: CEDERJ. Elaboração: NEGEF, 2019.

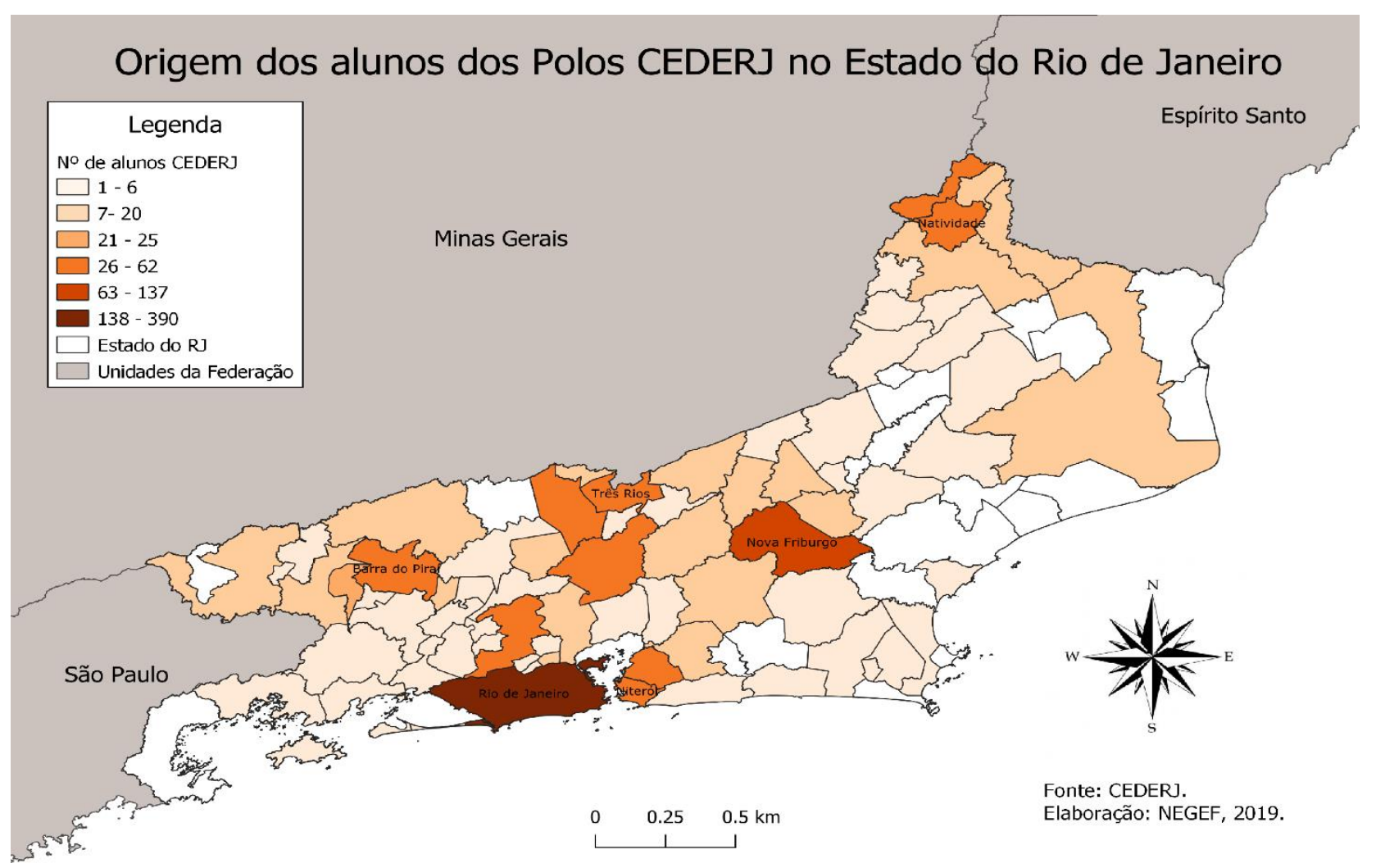


Nesse contexto, por meio de sondagem com os alunos participantes do curso de "Técnicas de Pesquisa", é que entendemos a importância de atividades extracurriculares para a formação discente, além de poder pautar a nossa atividade em uma prática interdisciplinar.

Desse modo, todos os participantes do curso foram unânimes em considerar que os objetivos propostos foram alcançados, contribuindo para a elucidação de inúmeras dúvidas com relação às etapas de uma pesquisa científica. Além disso, vale a pena destacar que ficou explícito na sondage a satisfação dos alunos com relação ao curso de Geografia UERJ/CEDERJ, considerando de excelente qualidade. Isso fica evidente quando percebemos afirmação como: "o curso vem contribuindo para me ajudar a encontrar a melhor maneira de ensinar, propondo ideias e soluções para um ensino de qualidade" (Resposta de aluno participante do curso "Técnicas de Pesquisa", 2018). Em um contexto geral, percebemos que a maioria dos alunos entendeu a proposta interdisciplinar do minicurso e reconheceu a sua importância para o desenvolvimento de suas práticas enquanto alunos e futuros profissionais: "O curso de Geografia contribui no sentido de construir uma visão crítica sobre a educação, trazendo à tona sempre a questão da prática em sala de aula" (Fala de aluno participante do curso "Técnicas de Pesquisa", 2019).

Ainda nesse contexto, a visão e reconhecimento que os alunos possuem sobre o curso de Geografia e a maneira como ele vem sendo administrado, corroboram com as nossas discussões de uma ciência que tenha uma utilidade prática na vida das pessoas e, no nosso caso, uma geografia que extrapole o ambiente escolar e desperte o interesse e entendimento do espaço em que vivemos por todos os envolvidos no processo educativo dos alunos. Sendo assim, "o curso de Geografia nos possibilita em todo momento a reflexão enquanto 'ser' inserido no espaço em constante transformação, logo, a formação enquanto docente da área tem sido fundamentada e enriquecida ao longo da realização do curso". (Depoimento de aluno participante do curso "Técnicas de Pesquisa", 2019).

Dessa forma, o reconhecimento do curso e suas diferentes atividades durante os períodos letivos, passam além da estrutura do currículo, mas também pela qualidade dos docentes e mediadores envolvidos nesse processo e essa consistência também está clara para o aluno, quando faz as suas considerações sobre o curso ministrado e o curso em geral: "O curso de Geografia vem me proporcionando segurança satisfatória com excelente material didático para estudo e me capacitando cada vez mais para a futura profissão" (Fala de aluno participante do curso "Técnicas de Pesquisa", 2018).

Diante desse contexto, acreditamos que o curso de Geografia desempenha papel de grande relevância na vida dos alunos, despertando o interesse constante pela pesquisa para o melhor entendimento do espaço geográfico e consequentemente aprimoramento de suas práticas enquanto futuros professores. Assim, como afirma CALLAI, (2005, p. 237) "fazer a análise geográfica significa dar conta de estudar, analisar, compreender o mundo com o olhar espacial". Esta é a nossa especificidade: por intermédio do olhar espacial, procurar 
compreender o mundo da vida, entender as dinâmicas sociais, como se dão as relações entre os homens e quais as limitações/condições/possibilidades econômicas e políticas que interferem.

A ideia defendida por Callai (2005) é corroborada com os depoimentos dos alunos, quando questionados acerca da contribuição que o curso de Geografia vem dando para a sua formação: "a Geografia dialoga com todas as disciplinas existentes; entendê-la é fundamental. Sem contar que o conhecimento geográfico nos dá senso crítico acerca do mundo e isso contribui para o nosso lado humano" (Fala de aluno participante do curso "Técnicas de Pesquisa”, 2019).

No entanto, não pretendemos discutir todos os aspectos imbricados nas questões, mas apresentar a preocupação central que esteve por trás da análise: o exercício de uma prática reflexiva e a formação de um professor pesquisador.

Assim, percebemos que esse pensamento se configura como uma prática constante no nosso curso, levando em consideração as falas dos alunos quando questionados sobre como o curso de Geografia vem contribuindo para a sua formação enquanto futuros professores - "O curso de Geografia nos desenvolve um olhar crítico, não só na relação homem - meio ambiente, mas atinge um leque amplo em relação homem mundo e nos prepara para futuros professores agentes mediadores no processo ensino-aprendizagem" (Fala de aluno participante do curso "Técnicas de Pesquisa", 2019).

Então, observamos que, dos alunos entrevistados, a maioria resgatou a questão interdisciplinar que vivencia no curso, além do estímulo em se pensar a prática docente, a realidade na qual o discente está inserido, para a construção do conhecimento em sala de aula, convergindo com as ideias discutidas no decorrer do texto sobre o professor reflexivo.

Ao que tudo indica e no exame dos dados, o conhecimento veiculado no curso em geral tenderá a ser utilizado pelo licenciando, futuro professor, como ferramenta de trabalho, existindo então uma relação entre esse conhecimento veiculado e sua formação; sem dúvida, uma exigência de nosso curso, objetivando uma formação satisfatória no sentido de atender às demandas da contemporaneidade.

De certo, o grande desafio para os cursos de formação docente é a legitimação dos professores recémformados a fim de que eles sejam reconhecidos como agentes de integração social.

Quaisquer que sejam os referenciais teóricos, o professor necessita compreender que os saberes docentes não podem ser reduzidos à transmissão de conhecimentos já instituídos, porque, em sua prática, são mantidas diferentes relações com diversos saberes, as quais têm enorme influência no processo educativo formal e, consequentemente, na construção autônoma do aprendizado dos alunos. 
Com relação à atividade do Seminário de Pesquisa, os alunos também foram consultados, com o intuito de averiguarmos se os objetivos de proporcionar a troca de experiências sobre os trabalhos desenvolvidos entre alunos de diferentes polos e discussão sobre as propostas de pesquisas individuais foram alcançados, bem como a satisfação por parte dos alunos participantes com relação ao seminário e se este contribui para a formação de professor pesquisador.

Outra vez, com base nos questionamentos levantados, observamos, pela fala da maioria dos alunos, que eles entendem o momento do Seminário de Pesquisa como de extrema importância para a troca de experiências e conhecimento e consequente aprimoramento para as suas pesquisas. Entre tantas declarações, a importância da troca de experiências com outros colegas e professores se mostrou evidente: "Sim [cumpre com o objetivo], pois é momento de troca de ideias com os colegas, e essa interação é importante para despertar novos horizontes para o saber geográfico" (Fala de aluno participante do "Seminário de Pesquisa", UERJ, 2019).

Outro fator importante no entendimento das atividades extracurriculares aqui discutidas é a formação de um professor que esteja preocupado com a realidade espacial na qual ele, os alunos e demais atores envolvidos no processo de ensino-aprendizagem estão inseridos. Consiste no processo de formação de um professor pesquisador, que esteja atento a esses fatores de mudanças constantes no espaço, e isso nos parece que está claro para os alunos de Geografia UERJ/CEDERJ: “O professor pesquisador faz da sua aula um constante objeto de pesquisa, tanto para promover a construção do conhecimento, como também para avaliar e melhorar a sua práxis docente; o que instrumentaliza sua prática diária" (Fala de aluno participante do "Seminário de Pesquisa", UERJ, 2019).

Além disso, percebemos que tanto o Seminário de Pesquisa quanto o curso Técnicas de Pesquisa vêm contribuindo para despertar nos alunos o exercício da pesquisa como ferramenta importante nas suas práticas diárias. Isso posto, consideramos que os objetivos dessas atividades estão sendo alcançados com excelência porque os alunos estão cada vez mais conscientes da importância da pesquisa para a formação de um professor pesquisador - "Todo contato com pesquisa contribui para a formação de um professor pesquisador, ainda mais com temas diversificados, locais distintos e realidades sociais e ambientais variadas. Essa abrangência de temas e produção e conhecimentos sempre traz aspectos positivos para a atuação de professores" (Fala de aluno participante do "Seminário de Pesquisa", UERJ, 2019).

Sendo assim, a leitura que fazemos está amparada nas respostas captadas. A partir dessa análise, tentamos generalizar, numa perspectiva qualitativa e interpretativa, nossas afirmações acerca da visão que os alunos - futuros licenciados do curso de Geografia - têm da atividade ora em pauta. 
A partir dos dados analisados, e ao que tudo indica, infere-se que o corpo de conhecimentos teóricos e práticos alocados nas atividades oferecidas tenderá a ser utilizado pelo futuro professor como ferramenta de trabalho. Existe, portanto, uma relação entre o conhecimento veiculado e a formação dos licenciandos.

Nesse sentido, percebemos a rica troca de experiência entre os participantes envolvidos nesses trabalhos - coordenadores de disciplinas, de curso e tutoria, mediadores e alunos. Por isso, essa aproximação vem promovendo a reflexão por parte desses atores de como se encontra estruturado o curso de Geografia na modalidade semipresencial e como as diferentes realidades encontradas podem interferir e contribuir para um resultado positivo nas futuras aprendizagens.

Não temos dúvida que um trabalho de formação que busque novas estratégias - no sentido de ajudar os futuros professores a introjetarem essa concepção de professor reflexivo e pesquisador, procurando sustentá-la em suas práticas - continue como um intensivo empenho e grande desafio por parte do curso de licenciatura em Geografia da UERJ/CEDERJ para provocar mudanças nas práticas escolares.

Bem sabemos que a tão desejada mudança nas práticas docentes passa necessariamente por uma boa formação inicial. Trabalhar com o eventual, sem mexer na formatação dos cursos de formação de licenciandos, é chover no molhado, ou seja, é cobrar do professor uma reflexão de práticas que, na verdade, para ele, são abstratas, dada a sua incapacidade de analisar as condições em que ocorrem (TEÓFILO, 2007).

Mais uma vez, recorremos a Callai (2013, p. 121), quando afirma:

Nesse sentido o próprio curso de graduação deve permitir aos licenciados que exercitem uma prática de sala de aula que não seja a mera repetição de conteúdos transmitidos a cada semestre, mas com uma linha metodológica que articule o ensino e a pesquisa. O professor da universidade deveria dar condições a que o próprio aluno consiga transformar as informações, as leituras, as discussões e exposições em sala de aula em um conhecimento organizado por ele próprio, isto é, que ele faça a construção de sua aprendizagem, exatamente aquilo que será exigido dele em sala aula dos Ensinos Fundamental e Médio.

\section{CONSIDERAÇÕES FINAIS}

Na verdade, os diferentes campos de conhecimento aqui elencados nos permitem entender que teoria e prática fazem parte de um processo, cuja apropriação deve ocorrer de forma simultânea, articulando o saber pesquisado com prática. Isso ocorre quando há a interiorização das teorias a partir da ação, e essa epistemologia prática é que permite a inteligibilidade de novas práticas.

A prática não basta ao professor, tornando-se essencial uma postura de constante pesquisador para que possa efetivamente construir um saber num movimento de reflexão, análise e problematização da ação na prática, pois conforme afirma Callai $(2010$, p. 36): 
A pesquisa na escola apresenta-se como a possibilidade de busca/investigação e produção do conhecimento. Um conhecimento que sirva para a vida do aluno, tanto na perspectiva de se reconhecer como um sujeito possuidor de uma identidade e que perceba seu pertencimento, como no desenvolvimento cognitivo que lhe permita ler o mundo, trabalhar nele tendo as condições necessárias para viver de modo digno.

No que tange aos cursos de formação de licenciandos, é preciso que os discentes criem uma cultura de análise em que os saberes científico, da docência e pedagógico não sejam entendidos como informação ou mera transmissão de conhecimento; ao contrário, articulem-se a fim de propiciar ao futuro professor a construção de uma postura crítica por meio da qual as práticas são problematizadas, permitindo, assim, uma aquisição refletida, o que sem dúvida irá favorecer uma aquisição refletiva.

A Universidade, enquanto espaço de formação, terá que pensar em um currículo que efetivamente estimule a reflexão, permitindo uma formação sólida, conjugando pesquisa e processo formativo, o que dará a verdadeira certificação ao futuro educador.

Nesse sentido, o curso de Geografia considera a pesquisa como fundamental nesse espaço de formação de licenciandos, entendendo que observar, perguntar, levantar hipóteses, interpretar a realidade, são ações que obrigam a rever conceitos aprendendo e reaprendendo.

Tendo em vista a pluralidade de alunos (licenciandos) que transitam nos diferentes polos e no ambiente da plataforma, entendemos que nossas práticas deverão ter como ponto de partida a experiência dos discentes, levando em conta seus diferentes ritmos, comportamentos, experiências, trajetórias pessoais - uma prática que procura embutir uma outra visão de aluno (ativo e interativo) e de mundo (complexo, em constantes transformações), melhor adequada ao contexto de EaD. Todas essas considerações apontam para um espaço que propicia a oportunidade de reconstrução do vivenciado e aprendido, a fim de que o futuro educador não tome os conhecimentos como rituais, cópias com imitações mecânicas de modelos fornecidos.

\section{REFERÊNCIAS}

CALLAI, Helena Copetti. “A Formação do Professor de Geografia”. Boletim Gaúcho de Geografia, 20: p. 39-41, dez., 1995.

"Aprendendo a ler o mundo: a Geografia nos anos iniciais do Ensino Fundamental". In: Cad. Cedes, Campinas, vol. 25, n. 66, p. 227-247, maio/ago. 2005.

. "Escola, cotidiano e lugar”. In: BUITONI, Marísia Margarida Santiago (Coord.). Geografia: ensino fundamental. Brasília: Ministério da Educação, Secretaria de Educação Básica, 2010, 252 p. (Coleção Explorando o Ensino, v. 22).

Formação profissional da geografia. ljuí: Ed. Unijuí, 2013.

DEMO, Pedro. Pesquisa e Construção do Conhecimento. Rio de Janeiro: Tempo Brasileiro, 2004.

FARIAS, Paulo Sérgio Cunha. "A interdisciplinaridade e as fronteiras do pensamento geográfico". In: FARIAS, Paulo Sérgio Cunha; OLIVEIRA, Marlene Macário de. (Orgs.). A formação docente em Geografia: teorias e práticas. Campina Grande: EDUFCG, 2014. 
GURGEL. Tais Cristina Nunes Pereira; SILVA, Cícero Nilton Moreira da. Geografia acadêmica e Geografia escolar: entorno de uma aproximação teórico-conceitual. III CONEDU: Congresso Nacional de Educação. Natal - RN. v. 1. Out/2016.

LUDKE, Menga (coord). O professor e a pesquisa. Série Prática Pedagógica. Campinas, SP, Papirus, 2001.

MELLO, Guiomar Namo de. "Manifesto dos Pioneiros da Educação Nova”. In: Revista Brasileira de Estudos Pedagógicos, n. 34, p. 79120, 1998.

. Magistério de 1o. Grau. Da competência técnica ao compromisso político. São Paulo: Cortez, 1998.

MENEZES, Victória Sabbado. "A historiografia da Geografia acadêmica e escolar: uma relação de encontros e desencontros". In: Geographia Meridionalis - revista eletrônica do Programa de Pós-Graduação em Geografia da Universidade Federal de Pelotas. v. 1, n. 2, Jul-Dez/2015, p. 343-362.

MORAES, Antônio Carlos Robert. Geografia Pequena História Crítica. 12 ed. São Paulo: Editora Hucitec, 1987.

NÓVOA, Antonio. Para o estudo sócio-histórico da gênese e desenvolvimento da profissão docente. Teoria e Educação, Porto Alegre, n. 4, p. 109-139, 1991.

PIMENTA, Selma Garrido. “A pesquisa em Didática 1995-1999”. In: CANDAU, Vera Maria (org). Didática, Currículo e Saberes Escolares. Rio de Janeiro, DP\&A, 2000.

e GHEDIN, Evandro (orgs.). Professor Reflexivo no Brasil: gênese e crítica de um conceito. São Paulo: Cortez, 2006.

PONTUSCHKA, N. N.; PAGANELLI, T. I.; CACETE, N.H. Para ensinar e aprender geografia. São Paulo: Cortez, 2009. 383 p.

SCHNITMAN, Dora (org.). Novos paradigmas, cultura e subjetividade. Porto Alegre: Artes Médicas, 1996.

SENNA, L. A. G. Linguagem e processos educacionais: visão de uma área de pesquisa da educação. Rio de Janeiro: Papel Virtual, 2002.

TEÓFILO, Vanilda M. S. Verdade e inclusão: perspectivas na formação de novos professores, 2007. Doutorado em Educação Programa de Pós-Graduação da Faculdade de Educação da Universidade do Estado do Rio de Janeiro (UERJ), 2007.

VIANA, Deise Miranda. "Formação do professor de física para o 2‥ Grau: a ciência como objeto de pesquisa". In: Anais da XVI Reunião anual da ANPED, Caxambu, 1996. 